\title{
The use of tools and approaches of system dynamics in the analysis of the efficiency of BIM implementation and its impact on the management and planning of investments in the construction sector
}

\author{
Martin Hotový ${ }^{1, *}$ \\ ${ }^{1} \mathrm{CTU}$, Czech Technical university in Prague, Faculty of Civil Engineering, Czech republic
}

\begin{abstract}
This paper presents the use of tools and approaches of system dynamics in the analysis of the efficiency of BIM tools implementation in relation to the management and planning of investments in the construction sector. The dynamic model based on the approach of system dynamics allows to simulate the impact rate (range) of BIM implementation in strategic investment decision-making in the construction sector. Based on the analysis, the key parameters critically affecting the large construction investment projects are determined. The proposed model is implemented as a submodel in the dynamic model designed for potential refinements in the strategic planning of the extent of investments into projects of civil infrastructure of the Czech Republic. The model allows to test different strategies in the virtual world before their implementation. The prediction of future developments based on the proposed model allows to streamline planning and decision-making processes.
\end{abstract}

\section{$1 \mathrm{BIM}$ in the construction sector}

Recently, in countries of the European Union as well as in other states outside this sector, BIM has been more and more involved in infrastructure projects. Primarily, its advantages have been used by architects, engineers and designers in early project stages and in project/construction implementation itself (see Fig. 1) PMI /1-3/, but BIM has also been applied throughout lifecycles of projects/constructions (see Fig. 1) BIM /1-4/.

$\mathrm{BIM}$ is a construction modelling process involving comprehensive information and information flows. It includes a 3D model that represents a physical and functional object with all its features and an open database with information about the construction that is shared by all stakeholders [1].

The benefits for the contractor can be summarized in the following main points:

- updated documentation available in time (updated databases)

\footnotetext{
* Corresponding author: martin.hotovy@,fsv.cvut.cz
} 
- early detection of collisions and errors in project drafts

- elimination of errors in production due to poor quality of projects

- better planning and coordination on construction sites

The benefits for investors are often mentioned as follows:

- adequate and appropriate information for assigning constructions

- better controllability during construction

- better decision-making and project management thanks to better-quality data available in time

- reduction of information noise from poor communication between project stakeholders

- reduction of time and costs

- sufficient amount of information for the next entire cycle of the project - especially in the operation phase

\section{Advantages of BIM}

The advantages of BIM are undeniable, and in many countries, they are considered so significant that they are mandatory for public tendering (primarily for infrastructure projects) - Denmark, Norway, Netherlands, Finland, and the United Kingdom. France will join these countries soon. Due to the unclear definition of BIM, however, the measurability of this methodology is very difficult.

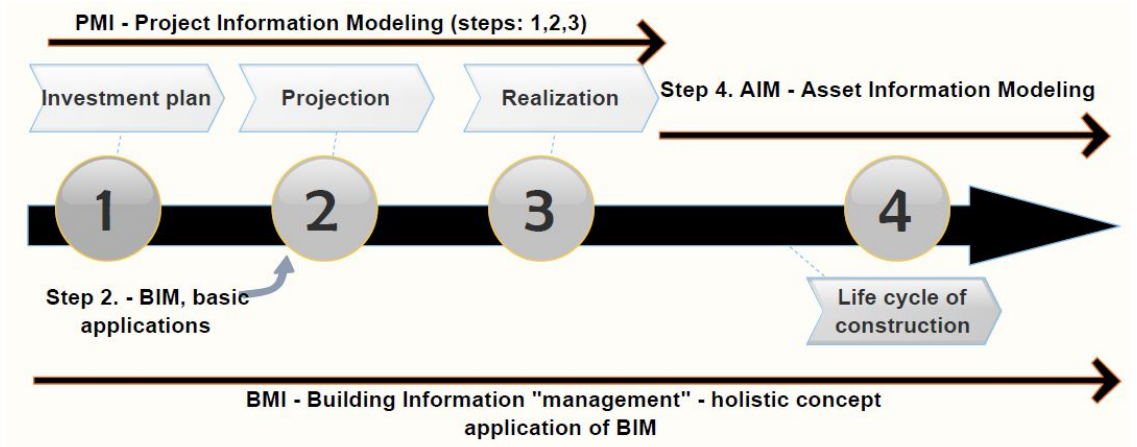

Fig.1. - taken over [1] and edited by the author

PMI - Project Information modeling

BIM „1“- Building Information modeling

AIM - Asset information modeling

BIM ,2“- Building information ,management“

In a holistic concept, some authors introduce PLMI (Project Live Modelling Information) instead of BIM "2", but in the overall concept of project life (LCC), it is not primarily about modelling, but rather about management of information and data (here I present Building Information "Management" as the better illustrative term (Fig.1.).

\section{Causal loop diagram as a tool for use of System Dynamics in BIM implementations process}

Causal loop diagram as a tool for use of System Dynamics [2,5] highlights feedback between entities as well as the facts that need to be taken into account in implementation and especially the long-term sustainability of BIM in the project. 


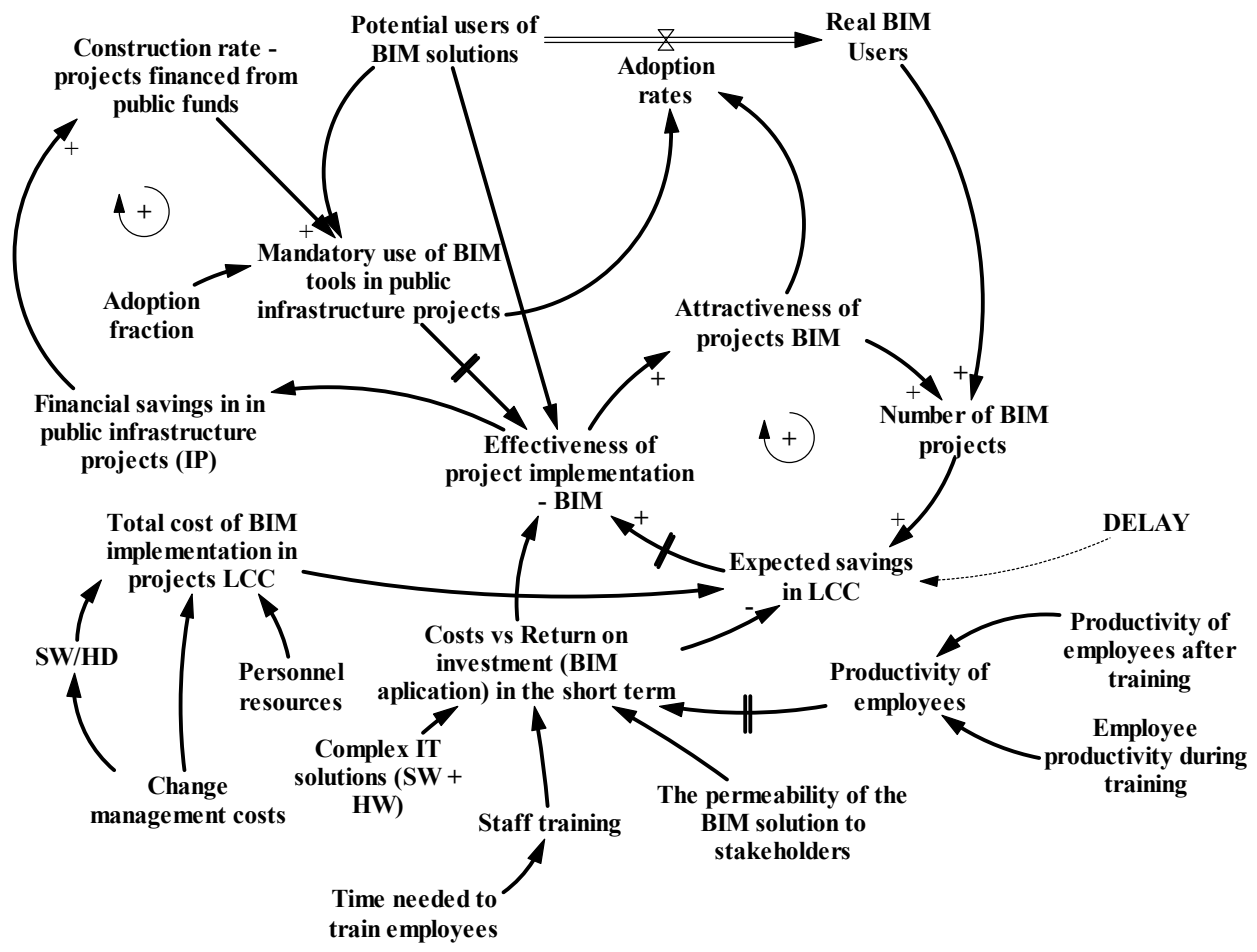

Fig. 2. Causal loop diagram of BIM implementation

The listed Causal loop diagram of BIM implementation (Fig. 2) clearly shows that some connections are "fundamentally" amplifying and support the use of BIM (marked with $\biguplus$ ).

The causal diagram indicates that there will be benefits in the operation phase of the building, but with delay brought by the rate of projects with the use of BIM and "delay" necessary to ensure and train sufficient human resources beyond the construction industry. I.e. BIM application / education at secondary and tertiary schools, which will provide suitably trained persons for the construction sector and sector of services relating to such projects. See Causal loop diagram of BIM implementation (Fig. 2) If there is a person who cannot work, or works wrongly with the BIM model, at any stage of the life cycle of a project, the economic advantages of using BIM may be interrupted/reduced.

\section{Basic attribute for the successful application of BIM tools}

The basic attribute for the successful application of BIM tools in construction industry is to increase the attractiveness of BIM in projects (see Figure 3.). I.e. by reducing obstacles (risks), which can be primarily perceived as follows [3]:

- insufficiency of resources (e.g. Staffing)

- inconsistent insights

- lack of data and information from BIM projects throughout project lifecycle

- rapid development

- necessary connection to sectors outside the construction sector and the relationship to its resources 


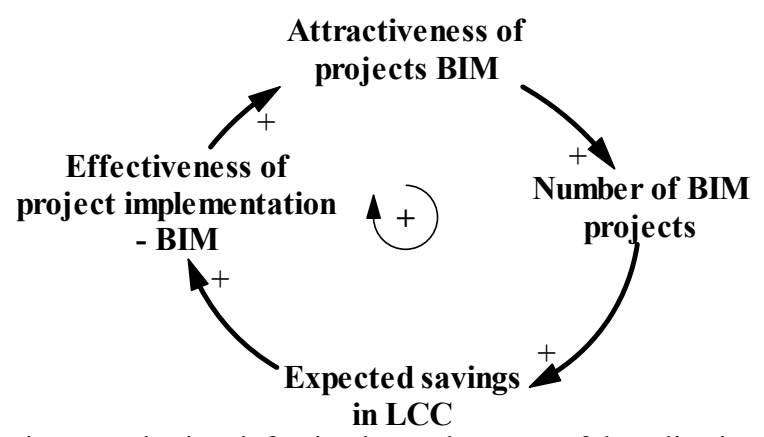

Fig. 3. Causal Loop Diagram - basic reinforcing loops the successful application of BIM tools

It is clear that for a maximum utilization of BIM application, i.e. a solution that maximizes savings [4] and other external benefits, it is necessary to create the appropriate conditions. These are mainly in the realization of the range of projects using BIM tools (e.g. making the use of BIM mandatory by law in infrastructure constructions and public tenders). This is illustrated by the second "amplifying" loop in the causal diagram (Fig. $3 ., 4)$.

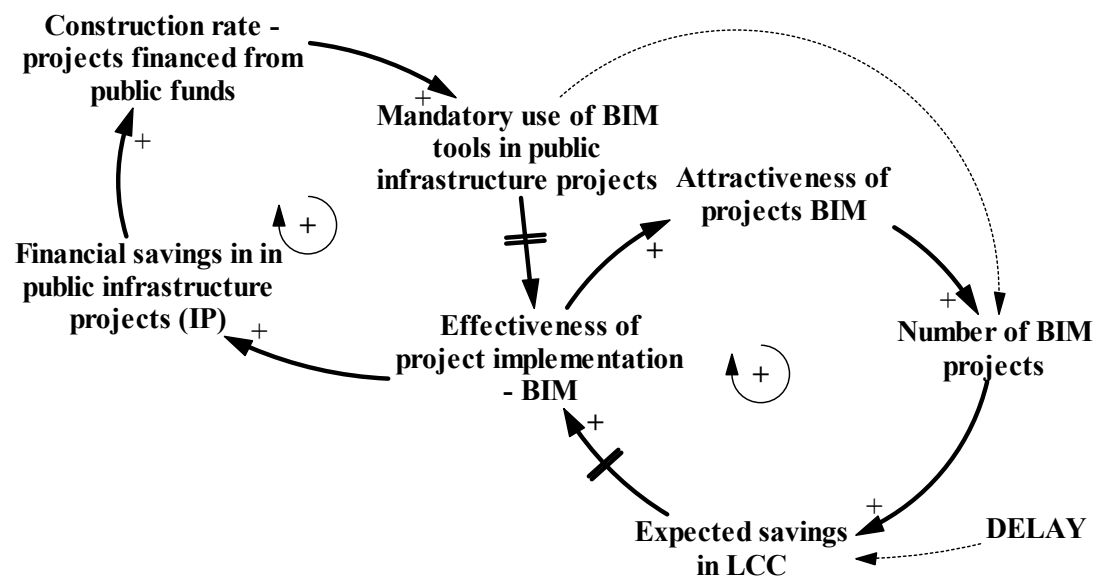

Fig. 4 Causal Loop Diagram - reinforcing loops BIM implementation with a certain delay

As illustrated by the Causal Loop Diagram (Fig. 1), it is necessary to secure sufficient resources for the use of BIM in the entire lifecycle of a project. This, however, will require costs for securing SW, HW and for the training of persons in facility management and other sectors. Ensuring sufficient human resources, which throughout entire project lifecycles come into contact with things that are necessary to be entered and updated in the BIM model, will certainly have a certain DELAY (Figure 1. and 4.)

\section{Project BIM manager}

Every project should have its BIM Manager, who would take care of BIM updates (and related BIM tools) for the current project. This, however, will require further costs for a number of years to decades. 
Believing that a BIM project may successfully take place during an entire project lifecycle without a project BIM Manager, where the environments Facility Management as well as other sectors outside construction are even less prepared for the application of BIM than project and design "sections" of construction, is currently very unclear.

\section{Conclusion}

There are very few projects in the Czech Republic that use BIM, there is not enough data to simulate and validate the model. We can, however, define the boundaries and submodels for integrating BIM in construction as a standard. This categorization then allows to analyse the possible weak points and the consequences that could surprise us in the future. However, there are expected benefits or situations where BIM may function under "incomplete" conditions throughout the entire LC:

- BIM may function even when not all stakeholders use it, but its efficiency (yield) is reduced.

- Training and resource costs will decrease over time, but there will be a step-up increase in costs in the initial phase of BIM implementation [4].

- Ownership costs of the model for its owners will gradually decrease over time due to savings and more qualified personnel.

- BIM will be the standard. The processes are already well defined and there is no need to wait. However, the system always impedes change, so these are now rather "waiting" stances.

In order to overcome this blocking link, it is mainly necessary to make a legislative step, i.e. to establish an obligation to use BIM and its standards when assigning and implementing public contracts for infrastructure projects. This will lead to the adoption of BIM tools in "major" companies, which will influence the adoption of BIM solutions and tools on the market as a whole, which will subsequently adopt it on the basis of these pilot references.

BIM should bring its advantages and benefits throughout the life cycle of the project, in involves entities other than those primarily related to construction (construction, production, etc.). The benefits will, in particular, be appreciated by: public authorities, certification, maintenance, energy companies, the IT sector, security, etc. If we manage to achieve this, especially infrastructure projects will see many economic benefits in the longterm, which will bring a positive amplifying feedback into the economy of the implementation of the solution and allow to strategically and better invest in other projects.

This work was supported by the Grant Agency of the Czech Technical University in Prague, grant No. SGS17/122/OHK1/2T/11.

\section{References}

1. P. Matějka, Building Information Modelaing (BIM) implementation related risk., 1, 92-94, (2017)

2. J. D. Sterman, Business Dynamics. Systems Thinking and Modeling for a Complex World, 1,136-141, (2000)

3. P. Matějka, N. Anisimova. Fundamentals of BIM implementation on the Czech construction market, 1, 69-86 (2012)

4. REVIT® Building Information Modeling: BIM's Return on Investment Autodesk (2017), Available on http://www.autodesk.com/revit

5. D. Vytlačil, System analysis and synthesis, 1, 27-28 (2007) 